\title{
Oficina de Habilidades Sociais Para Promoção do Bem-Estar em Jovens da Guarda Mirim de Foz do Iguaçu no Início da Vida Profissional
}

Aline Almeida Cabanha1, Maria Necilene Matias² e Meire Perpetua Vieira Pinto ${ }^{3}$.

1. Graduanda em Psicologia (Uniamérica 2019).

2. Técnóloga em Processamento de Dados (CESUFOZ-2004); Graduanda em Psicologia (Uniamérica).

3. Professor Orientador do Curso de Psicologia, Centro Universitário União das Américas - Uniamérica.

line_cabanha@hotmail.com enecilene@gmail.com

\section{Palavras-chave}

Autoconhecimento

Autoexposição

Habilidades Sociais de trabalho

Juventude

Artigo recebido em: 24.01.19

Aprovado para publicação em: 24.05.19

\begin{abstract}
Resumo: As Habilidades Sociais são consideradas essenciais no ambiente de trabalho. Jovens que possuem um bom reportório dessas habilidades têm maior probabilidade de sucesso no início da vida profissional. Objetivo. Avaliar as Habilidades Sociais de alunos participantes do último ano do programa para jovens com inserção no mercado de trabalho, da Guarda mirim de Foz do Iguaçu, e desenvolver oficinas para promover estas habilidades a fim de refletir no repertório destes em sua vida pessoal e profissional. Metodologia. Pesquisa de campo de caráter descritivo, de natureza qualitativa e quantitativa com 24 alunos com idades de 16 a 18 anos. Para levantamento de dados foram realizadas entrevistas com as psicólogas da instituição e aplicação do Inventário de Habilidades Sociais (IHS) nos alunos. Foram realizados 9 encontros, constituídos por oficinas abordando vivência grupal, dinâmicas, palestra, vídeo, roda de conversa, jogos de cartas da autoestima e roleta das habilidades sociais. Resultados. Constatou-se através do IHS um baixo repertório de HS com um maior déficit no fator que avalia a autoexposição. Os comportamentos analisados durante as oficinas confirmaram um alto grau de resistência nas atividades que requeriam exposição, confirmando os resultados da análise quantitativa do Inventário de Habilidades Sociais. Conclusão. O desenvolvimento das oficinas buscou contribuir para melhorar essa habilidade nos alunos e refletir de forma positiva no comportamento pessoal e profissional. Através dos relatos verbais foi possível observar a eficácia das oficinas bem como uma melhora inclusive na interação da turma.
\end{abstract}

\section{INTRODUÇão}

O renomado casal de pesquisadores brasileiros, reconhecidos nacional e internacionalmente no campo da psicologia das habilidades sociais, Del Prette e Del Prette (2017), reforça que, nos últimos vinte anos é possível observar no país a presença crescente do tema nos principais congressos, simpósios, revistas científicas e publicação de livros, assim como o interesse no campo da teoria, prática e pesquisa. Tais habilidades são requisitadas para interações sociais satisfatórias, sendo consideradas como mecanismos de proteção da saúde física, mental e do bem-estar. Com os novos padrões organizacionais, o ambiente de trabalho exige cada vez mais habilidades interpessoais da equipe, sendo que raramente tais habilidades são temas abordados em instituições de ensino ou em treinamentos de empresas. Porém, de acordo com a última versão da Base Nacional Comum Curricular - BNCC (2016), fica formalizado que a partir de 2019 os estudantes possam, no ambiente escolar, desenvolver dez competências gerais, com o intuito de mobilizar conhecimentos acerca de conceitos e procedimentos, habilidades cognitivas, socioemocionais e práticas, assim como atitudes para re- 
solução de conflitos, exercício da cidadania e do mundo de trabalho. Entre as competências, a oitava, nona e décima aplicam-se ao desenvolvimento de habilidades sociais:

8-Conhecer-se, apreciar-se e cuidar de sua saúde física e emocional, compreendendo-se na diversidade humana e reconhecendo suas emoções e as dos outros, com autocrítica e capacidade para lidar com elas.

9-Exercitar a empatia, o diálogo, a resolução de conflitos e a cooperação, fazendo-se respeitar e promovendo o respeito ao outro e aos direitos humanos, com acolhimento e valorização da diversidade de indivíduos e de grupos sociais, seus saberes, identidades, culturas e potencialidades, sem preconceitos de qualquer natureza.

10-Agir pessoal e coletivamente com autonomia, responsabilidade, flexibilidade, resiliência e determinação, tomando decisões com base em princípios éticos, democráticos, inclusivos, sustentáveis e solidários (BNCC, 2016, p. 9).

Sendo considerado importante o desenvolvimento de habilidades sociais no início da vida profissional, foram avaliadas as HS de jovens da Guarda Mirim de Foz do Iguaçu, com o intuito de promover o bem-estar, realizando oficinas com aplicação de dinâmicas, rodas de conversa, vídeos, atividades de autoconhecimento, aplicação de baralho e roleta, ambos terapêuticos, confeccionados pelas próprias acadêmicas de Psicologia. Após a aplicação do Inventário de Habilidades Sociais (IHS), identificou-se repertório deficitário em todas as subclasses de habilidades, principalmente no fator F4, que corresponde a autoexposição a desconhecidos e situações novas, o que foi comprovado pela observação do comportamento dos jovens ao longo das oficinas.

\section{Fundamentação Teórica}

As habilidades sociais, são construtos descritivos dos comportamentos sociais aprovados culturalmente, que geram alta probabilidade de resultados positivos para o indivíduo e sua comunidade, ao passo que contri buem para a competência social. Referem-se às diversas classes de comportamentos sociais do repertório do sujeito, favorecendo relações saudáveis. Pesquisas realizadas nesse tema demonstram que para o desenvolvimento de relacionamentos bem-sucedidos, é necessário identificar em quais situações será adequado emitir determinado comportamento (DEL PRETTE; DEL PRETTE, 2013a; 2017). Complementando a linha de raciocínio, Caballo (2006, p. 6), define que as habilidades sociais são:

[...] um conjunto de comportamentos emitidos por um indivíduo em um contexto interpessoal que expressa sentimentos, atitudes, desejos, opiniões ou direitos desse indivíduo de modo adequado à situação, respeitando esses comportamentos nos demais e que geralmente resolve os problemas imediatos da situação enquanto minimizando a probabilidade de futuros problemas.

\section{Habilidades Sociais e Bem-estar}

Segundo Silva (2018), nem todas as pessoas têm a facilidade de comunicar-se bem, de forma clara e as sertiva. Pessoas com dificuldades de comunicação podem sofrer de forma considerável. Além de não pertencer a um grupo social, um déficit nessas habilidades pode provocar bastante ansiedade. Em Del Prette e Del 
Prette (2017), pesquisas referentes ao campo das Habilidades Sociais demonstram que um repertório elaborado pode agir como papel protetor na evitação do desenvolvimento de transtornos psicológicos. Em indivíduos com bom repertório, é possível observar maior qualidade de vida, realização profissional, autoconfiança, otimismo, resiliência, relacionamentos mais saudáveis etc. Tais aspectos se relacionam com indicadores de bem-estar, que se apresentam mais próximos e condizentes com o conceito de saúde proposto atualmente. Estudos no campo de Treinamento de Habilidades Sociais apontam que indivíduos competentes socialmente possuem relações pessoais e profissionais mais satisfatórias, assim como melhor saúde mental e física. Em contrapartida, os déficits em habilidades sociais são considerados fatores de risco para a atuação psicossocial do indivíduo, por se relacionarem a conflitos nas relações interpessoais, pior qualidade de vida e transtornos psicológicos específicos, como, por exemplo, depressão, ansiedade, dificuldades de aprendizagem, isolamento social, problemas de comportamento internalizantes e externalizantes (DEL PRETTE; DEL PRETTE, 2014a; 2017).

\section{Habilidades Sociais de trabalho}

Segundo Del Prette e Del Prette (2014a), praticamente nenhuma profissão é realizada fora de um contexto social. Enquanto existem trabalhos que são majoritariamente individuais, outros exigem atividades que dependem totalmente da relação e interação com o outro. Para Brantes e Gondim (2014), as exigências e padrões do mercado de trabalho têm se atualizado nos últimos anos, onde é possível observar maior cobrança do colaborador sobre as noções de competência na atualidade.

As organizações realizam processos seletivos para escolha de candidatos, a fim de avaliar se o indivíduo terá o desempenho esperado para as tarefas propostas. Além, o próprio jovem ingressante no mercado de trabalho passa por um processo de indagação acerca de suas competências, exigidas para o sucesso profissional (BRANTES; GONDIM, 2014). São demandadas do indivíduo habilidades específicas, chamadas de habilidades sociais profissionais, que "são aquelas que atendem às diferentes demandas interpessoais do ambiente de trabalho objetivando o cumprimento de metas, a preservação do bem-estar da equipe e o respeito aos direitos de cada um”. (ARGYLE,1980 apud DEL PRETTE; DEL PRETTE, 2014a, p.89).

Ainda de acordo com estes mesmos autores, Del Prette e Del Prette (2014a), das diversas habilidades existentes, quatro são consideradas indispensáveis para as atividades organizacionais, que são as habilidades de coordenar grupos, falar em público, resolução de conflitos e habilidades sociais educativas. A coordenação de grupos está ligada ao conceito de liderança, que consiste na promoção e articulação do desempenho dos participantes no alcance de metas, objetivos e consecução de tarefas, ao passo que fornece feedback positivo, propõe normas junto da equipe etc. Habilidade para falar em público é requerida no contexto profissional, sendo rotineira em reuniões, apresentação de tarefas e projetos, treinamento e orientações. Além da necessidade de controlar a ansiedade, o indivíduo deverá ter domínio do conteúdo a ser exposto, se monitorar ao longa da fala, prever estratégias para as reações dos ouvintes, assim como fazer uso de habilidades verbais, como responder e elaborar perguntas, lidar com críticas e imprevistos, estar atento ao tom de voz, ges tos, contato visual e postura.

No que tange à resolução de conflitos, é necessário reconhecer que em todas as organizações haverá pro blemas, que terão suas soluções prejudicadas por fatores como ansiedade excessiva, falta de motivação e déficits em habilidades sociais. As habilidades sociais educativas são aquelas que promovem a aprendizagem do outro, sendo importante no contexto organizacional para a transmissão de conteúdos, por exemplo. Por 
fim, é necessário levar em consideração que essas habilidades não são pertinentes apenas à área profissional, assim como não se deve excluir outras não mencionadas (DEL PRETTE; DEL PRETTE, 2014a).

\section{Autoconhecimento}

Para que as relações sejam satisfatórias, ou seja, competentes socialmente, é necessário que o indivíduo tenha autoconhecimento e conhecimento sobre o ambiente que o cerca, sendo que o autoconhecimento consiste, segundo Del Prette e Del Prette (2012), no conhecimento de si mesmo, tendo como requisito as habili dades de identificar as próprias emoções, os comportamentos a elas relacionados, os valores subjacentes e as autorregras. É importante para a competência social no sentindo de que, segundo Skinner (1974), conforme citado por Del Prette e Del Prette (2017, p. 61) “é a base para a previsão e controle dos próprios comportamentos em interações no mundo social”. Portanto, em Treinamentos de Habilidades Sociais, é de extrema importância que lacunas sobre o autoconhecimento sejam supridas.

\section{Autoexposição a Desconhecidos e Situações Novas}

A autoexposição é a exposição de si próprio. Neste sentido, conforme pontuam Del Prette e Del Prette (2014b) a autoexposição a desconhecidos e situações novas inclui basicamente a abordagem a pessoas desconhecidas, fazer perguntas a desconhecidos; pedir favores a desconhecidos, falar a público desconhecido e falar a público conhecido. Dentro deste contexto, fazer uma palestra, apresentar-se em uma entrevista de trabalho, realizar uma exposição oral a pessoas tanto conhecidas como desconhecidas, entre outras formas de autoexposição, carecem desta habilidade para que se possa obter resultado satisfatório dentro das competências sociais.

\section{MÉtodo}

\section{Caracterização do ambiente Pesquisado}

O projeto foi desenvolvido na Guarda Mirim de Foz do Iguaçu, inaugurada em 26 de julho de 1977, Ins tituição que tem como missão promover a formação técnico-profissional de adolescentes de ambos os sexos e de diferentes classes sociais, na faixa etária de 14 a 18 anos. Em uma apresentação de demandas, realizada pelas psicólogas da instituição, relatou-se a necessidade de serem trabalhadas as habilidades sociais desses jovens, tendo em vista, reclamações reportadas pelos empresários da cidade de que os jovens que estão ingressando no mercado de trabalho apresentam déficits na interação social.

\section{Método de Abordagem}

O trabalho proposto trata-se de uma pesquisa de campo de caráter descritivo, com natureza qualitativa e quantitativa. O objetivo foi avaliar as Habilidades Sociais de alunos participantes do último ano do programa para jovens com inserção no mercado de trabalho, da Guarda mirim de Foz do Iguaçu, e desenvolver oficinas para promover estas habilidades a fim de refletir no repertório destes em sua vida pessoal e profissional. A coleta de dados consistiu em entrevista semiestruturada com as psicólogas da instituição para verificação da demanda e problemática. 


\section{População}

A escolha do local foi do tipo intencional ou seleção racional, principalmente pelo fato do interesse e necessidade da Instituição em se submeter ao estudo proposto. A amostra foi composta por 24 alunos, sendo 12 do sexo masculino e 12 do sexo feminino, matriculados no último ano do processo de aulas da Guarda Mi rim, ou seja, saindo dali diretamente para o mercado de trabalho. As idades médias desses alunos variam de 16 a 18 anos.

\section{Materiais e instrumentos}

Para avaliar as Habilidades Sociais dos alunos aplicou-se o Inventário de Habilidades Sociais (IHS) que produz um escore geral e escores em fatores: F1-Enfrentamento com risco, F2-Autoafirmação na expressão de afeto positivo, F3-Conversação e desenvoltura social, F4-Autoexposição a desconhecido ou a situações novas, F5-Autocontrole da agressividade a situações aversivas (DEL PRETTE; DEL PRETTE, 2014b). O autoconhecimento foi analisado através de uma tarefa de auto-observação e aplicação de um jogo de baralho terapêutico intitulado "baralho da autoestima", sendo este uma criação das próprias acadêmicas. Para reforçar a promoção das habilidades sociais, as acadêmicas elaboraram uma roleta interativa, onde os alunos deveriam responder questões relacionadas com as habilidades sociais de trabalho, tendo como foco a autoexposição dos jovens.

\section{Procedimento}

Foram realizados 9 encontros para o desenvolvimento do projeto, sendo um deles para alinhamento da demanda com as psicólogas, e 8 encontros em forma de oficinas para promover as habilidades sociais dos alunos.

As atividades tiveram início em 16 de agosto de 2018 e finalização em 26 de outubro de 2018, realizados no período matutino com duração de 50 minutos a cada manhã. Durante as atividades foram aplicadas práticas de vivência grupal, dinâmicas, palestra, vídeo, rodas de conversa, tarefa de casa, jogo de baralho da autoestima, roleta das habilidades sociais.

A manhã do dia 16/08/18 foi dedicada à reunião com as psicólogas da instituição e teve como objetivo obter maiores detalhes sobre o público-alvo, conhecer melhor a demanda e definir dias e horários para a realização das oficinas.

Para avaliar qual habilidade a ser trabalhada com os alunos, foi aplicado o Inventário de habilidades sociais no dia 24/08/18.

No dia 31/0818, além da devolutiva geral do IHS, foi trabalhada a Dinâmica do desafio para explorar o medo ao desconhecido, timidez e oportunidades na vida. Já no terceiro encontro, na data 14/09/18, foram realizadas as devolutivas individuais do IHS antes do horário de início da oficina. As atividades neste dia objetivaram explicar as habilidades sociais de forma interativa, utilizando placas que continham subclasses de habilidades sociais para, desta forma, levar os alunos a uma reflexão sobre as habilidades que mais se lhe destacam e as que precisam ser trabalhadas.

Durante a oficina realizada no dia 21/09/18 o tema desenvolvido foi o autoconhecimento. Houve apresentação de um vídeo sobre "Autoconhecimento na carreira”; realizou-se uma roda de conversa sobre os 
principais pontos identificados no vídeo. Logo após, foi dada uma tarefa de auto-observação para ser realizada durante a semana. O feedback da tarefa de observação foi realizado no dia 28/09/18, seguido do jogo de "Baralho da autoestima”, com objetivo de reforçar o autoconhecimento. Dando continuidade ao jogo do Baralho da Autoestima, o mesmo foi utilizado na oficina do dia 05/10/18, como forma de reforçar o conceito do autoconhecimento.

Na penúltima oficina realizada no dia 19/10/18, a atividade proposta teve como finalidade trabalhar a autoexposição dos alunos através de uma atividade de identificar comportamento passivo/agressivo e aplicar uma resposta assertiva para a situação.

O encerramento das oficinas foi realizado no dia 25/10/18. Iniciou-se a proposta com a atividade da Roleta das Habilidades Sociais, objetivando reforçar as habilidades sociais de trabalho de forma interativa. Logo após, os alunos praticaram a habilidade de autoexposição, apresentando verbalmente para toda a turma um tema de sua preferência antecipadamente escolhido para essa. Dando seguimento, realizou-se uma roda de conversa para feedback das oficinas. Em seguida, procedeu-se à entrega dos certificados de participação e um coffee-break.

\section{Resultados e Discussões}

De acordo com os dados obtidos pela aplicação do Inventário de Habilidades Sociais (IHS) dispostos em anexo na Tabela 1, identificou-se que apenas 01 (6\%) dos 17 alunos avaliados obteve índice de repertório de habilidades sociais bem elaborado, 05 (29\%) obtiveram índice de repertório bom acima da média, nenhum respondente obteve classificação mediada, 05 (29\%) obtiveram resultado abaixo da média e 06 (35\%) obtiveram resultados com indicações de treinamento de habilidades sociais. Ainda que os resultados obtidos demonstrem de forma geral um déficit nas habilidades trabalhadas e, considerando a idade jovem desses alunos, corroboram com o que postula a literatura, bem como enfatiza DEL PRETTE; DEL PRETTE (2005) que o desenvolvimento das habilidades sociais tem início no nascimento e se torna progressivamente mais elaborado ao longo da vida. Sendo assim, é comum que resultados de habilidades sociais de adolescentes e jovens apresentem índices abaixo da média.

Quanto aos escores por subclasses de habilidades sociais, representados na Tabela 2, eles indicam um repertório baixo em todos os fatores. O F1 que avalia situações de enfrentamento e autoafirmação com risco apresentou um escore em percentil de 23\%, o F2 que avalia a autoafirmação na expressão de sentimentos positivos obteve um percentil de 31\%, já o F4 que avalia situações de autoexposição a desconhecidos e situações novas apresentou um percentil de $21 \%$ e o F5 que avalia o autocontrole da agressividade pontuou com $40 \%$ do percentil. As oficinas de habilidades sociais tiveram como foco a subclasse (F4) autoexposição a desconhecidos e situações novas, por ter obtido o resultado mais baixo (21\%) entre as demais subclasses. Essa categoria de habilidades sociais de acordo com Del Prette e Del Prette (2014b) inclui abordagem a pessoas desconhecidas, fazer perguntas a desconhecidos; pedir favores a desconhecidos, falar a público desconhecido e falar a público conhecido. Durante as oficinas foi possível observar uma grande resistência dos alunos ao serem requeridas atividades onde deveriam realizar exposições orais, ou seja, falar em público, sendo estes comportamentos possivelmente consequências do déficit no fator F4 das habilidades sociais.

Nas atividades envolvendo o Jogo do Baralho da Autoestima, foi possível observar através das respostas dos alunos dificuldades em expressar ou dizer o que estão sentindo por receio da autoexposição. Esta mesma dificuldade surgiu durante a dinâmica com a Roleta das Habilidades Sociais, onde, além de responder à situ- 
ação estabelecida, o aluno deveria se levantar e ir até a frente da sala para girar a roleta. Percebe-se que quanto maior o nível de exposição, maior a resistência em realizar a atividade. Conforme relatos dos próprios alunos ao serem questionados sobre a resistências às atividades de autoexposição, eles dizem que: "sentem vergonha”, "tem medo de errar diante dos demais colegas”, “ansiedade e parece que a voz não quer sair”, “pânico de falar em público”, "prefiro perder nota do que ter que ir falar lá na frente da sala”. A partir desta análise, fica clara a importância de se desenvolver um bom reportório de habilidades sociais, como enfati zam Del Prette e Del Prette (2005; 2017), um repertório elaborado de Habilidades Sociais é considerado um fator de proteção, pois é um indicador de ajustamento psicossocial, de desenvolvimento saudável e de qualidade de vida. Além disso Del Prette e Del Prette (2013b) destacam que os jogos são utilizados com objetivos educacionais distintos como socialização, transmissão de valores e desenvolvimento de autonomia.

No encerramento das oficinas, ao ser realizado um feedback dos encontros, foi possível observar através dos relatos dos alunos um entendimento e compreensão da proposta do nosso trabalho, como também o reconhecimento de qualidades/debilidades, e uma significante melhora na interação da turma em sala de aula:

"Aprendi muito a me conhecer melhor";

"Melhorou a interação com a turma, antes quase ninguém se falava, agora as pessoas conversam mais umas com as outras";

"Antes não me colocava no lugar do outro, tinha uma pessoa na turma que eu pensava uma coisa dela, agora que conheci um pouco mais sobre a história dessa pessoa posso entender muitas coisas que antes não entendia";

"Sei que posso dizer não sem ofender a outra pessoa";

"Foi legal, e agora já sei o que são habilidades Sociais";

"Eu não sabia antes o que era assertividade";

"Tenho vergonha de me expor, mas agora eu sei que tenho que praticar para ir perdendo essa vergonha";

“Tenho muita vergonha de falar em público, o projeto ajudou, mas ainda tenho vergonha”; "Posso colocar em prática tudo que aprendi no meu trabalho, pude descobrir que sou assertiva e isso vai me ajudar bastante";

"A maior diferença que observei foi dentro da sala de aula, as pessoas interagem mais agora".

\section{Conclusão}

De acordo com os dados apresentados verificou-se que as oficinas realizadas possibilitaram uma melhor compreensão do que são as habilidades sociais aos alunos, bem como a importância de se desenvolvê-las, principalmente para que se possam estabelecer um bom relacionamento e desempenho social no ambiente de trabalho. Trabalhar o autoconhecimento contribuiu de forma relevante para que estes jovens pudessem conscientizar-se de suas qualidades e debilidades na interação social.

Pelo fato de o trabalho ter sido desenvolvido em grupo possibilitou-se uma maior variedade de interações interpessoais, porém, cabe ressaltar que a devolutiva do IHS realizado individualmente garantiu a discussão com maior profundidade dos déficits e qualidades encontradas no resultado de cada participante em particular. A escuta ativa, o acolhimento e a explicação de cada fator avaliado no inventário, durante as devolutivas individuais, contribuíram para que o aluno pudesse se sentir único e propiciar um vínculo com as aca dêmicas o que consequentemente facilitou no manejo das oficinas. 
Através dos relatos foi possível observar a eficácia da proposta, porém isto não garante que os participantes agirão de forma habilidosa sempre que se depararem com situações que requerem um bom repertório destas habilidades. Devido ao tempo limitado das oficinas, não foi possível mensurar através de forma quantitativa uma melhora nas habilidades sociais e do bem-estar dos participantes, nem tampouco no fator mais deficitário que é a autoexposição. Por outro lado, é indicado um Treinamento de Habilidades Sociais (THS) para que se possa obter um resultado mais consistente e satisfatório, tendo em vista que de modo geral, com exceção de 01 aluno, os demais obtiveram resultados abaixo da média no Inventário de Habilidades Sociais.

\section{REFERÊNCIAS}

BRANTES, C.A.A.; MORAIS, F.A.; GONDIM, S.M.G.S. Competências Socioemocionais: Fator-Chave no Desenvolvimento de Competências para o trabalho. Revista Psicologia: Organizações e trabalho, v. 14, n. 4, p. 394-406, out./dez., 2014.

BRASIL. Ministério da Educação. Base Nacional Comum Curricular. Proposta preliminar. Segunda versão revista. Brasília: MEC, 2016. Disponível em: <http://basenacionalcomum.mec.gov.br/images/BNCC_publicacao.pdf>. Acesso em: 06 abr. 2018.

CABALLO, V.E. Manual de Avaliação e Treinamento de Habilidades Sociais. São Paulo: Santos, 2006.

DEL PRETTE, A.; DEL PRETTE, Z. A. P. Psicologia das Relações Interpessoais: Vivências Para o Trabalho em

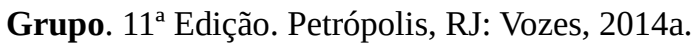

DEL PRETE, Z. A. P.; DEL PRETE, A. Competência Social e Habilidades Sociais: Manual Teórico-Prático. Petrópolis: Vozes, 2017.

DEL PRETE, Z. A. P; SOARES, A. Habilidades Sociais Diálogos e Intercâmbios Sobre Pesquisa e Prática. Novo Hamburgo: Sinopsys, 2015.

DEL PRETE, Z. A. P.; DEL PRETE, A. Inventário de Habilidades Sociais (IHS-Del Prette): Manual de Aplicação, Apuração e Interpretação. 5. ed. São Paulo: Casa do Psicólogo, 2014b.

DEL PRETE, Z. A. P.; DEL PRETE, A. Psicologia das Habilidades Sociais na Infância: Teoria e Prática. Petrópolis, RJ: Vozes. 2005.

DEL PRETE, Z. A. P.; DEL PRETE, A. Psicologia das Habilidades Sociais na Infância: Teoria e Prática. 6. ed. Petrópolis: Vozes, 2013b.

DEL PRETE, Z. A.P.; DEL PRETE, A. Psicologia das Habilidades Sociais: Diversidade Teórica e suas Implicações. 3. ed. Petrópolis: Vozes, 2013a.

DEL PRETE, Z. A. P.; DEL PRETE, A. Psicologia das Habilidades Sociais: Terapia, educação e trabalho. 9. ed. Petrópolis: Vozes, 2012.

SILVA, C.M.A.C. Habilidades Sociais na Clínica Psicológica. Revista Sustinere, RJ. Vol. 6 n. 1, p. 134-149, jan./jun., 2018. 